\title{
Intracranial Telemetry Recording of Intractable Epilepsy at London Health Sciences Centre
}

\author{
David A. Steven, Richard S. McLachlan
}

\begin{abstract}
Routine EEG telemetry using scalp electrode recordings is carried out in all patients being considered for epilepsy surgery. However this, along with other testing, may not yield sufficient information about the location of seizure onset to allow a decision regarding surgery to be made. Various methods have been developed to implant electrodes for chronic recording closer to the cortical surface from which seizures arise including the use of sphenoidal, foramen ovale, epidural peg, subdural and depth electrodes. This is a review of the last two techniques particularly as utilized at London Health Sciences Centre.
\end{abstract}

RÉSUMÉ: Enregistrement intracrânien par télémétrie de l'épilepsie pharmacorésistante au London Health Sciences Centre. L'enregistrement ÉEG par télémétrie au moyen d'électrodes appliquées sur le cuir chevelu est fait de routine chez tous les patients évalués en vue d'une chirurgie de l'épilepsie. Cependant cet enregistrement, ainsi que les autres tests effectués, ne fournissent pas toujours suffisamment d'information sur le site où les crises prennent naissance pour permettre de prendre une décision concernant la chirurgie à effectuer. Différentes méthodes ont été développées pour implanter des électrodes afin de procéder à un enregistrement prolongé plus près de la surface corticale au site où les crises prennent naissance dont l'utilisation d'électrodes sphénoïdales, d'électrodes du trou ovale, d'électrodes épidurales PEG, d'électrodes sous-durales et d'électrodes profondes. Nous revoyons l'utilisation de ces deux dernières techniques au London Health Sciences Centre.

Successful epilepsy surgery depends on the ability to identify the epileptogenic zone. Often this can be achieved with standard non-invasive investigations, including a detailed history and physical, scalp electroencephalography (EEG), structural magnetic resonance imaging (MRI), a neuropsychological evaluation and functional neuro-imaging. ${ }^{1}$ In cases where the non-invasive investigations identify a clear area of onset, resective surgery can be recommended without further study. However in many cases the epileptogenic zone cannot be readily identified, particularly when there is discordant or ambiguous EEG data. In these instances, invasive electroencephalography is often required. Invasive monitoring is usually carried out with depth electrodes ${ }^{2-5}$, subdural electrodes ${ }^{6-9}$, or a combination of both $^{10-12}$.

Should depth or subdural recording be done in all patients before epilepsy surgery?

In the past (roughly 1970 to 1990 ) there have been two schools of thought about this question. Several American and European epilepsy centres required invasive recordings usually with depth electrodes in all patients ${ }^{13}$ whereas the Montreal Neurological Institute, with arguably the most experience in the surgical treatment of epilepsy at the time, argued that the added risk and expense of invasive recording was only necessary when careful extracranial recording supplemented by additional nonelectrophysiological data did not solve the problem of localization. ${ }^{14}$

As neuroimaging technology such as MRI, PET and SPECT emerged $^{15}$ to provide important supportive localizing information to that provided by EEG, the tendency for some centres to require invasive recording in all patients has diminished. However the level of comfort that the clinically relevant seizure focus has been accurately identified without invasive recordings remains quite variable not only from centre to centre but also between individual clinicians. In the event of differences in opinion about the need for invasive recording in any one case, the final determination must be made by the epilepsy surgeon.

From the Epilepsy Program, Western University, University Hospital, London, Ontario, Canada.

Received January 26, 2012. Final Revisions Submitted August 7, 2012. Correspondence to: Richard S McLachlan, Epilepsy Programme, Department of Clinical Neurological Sciences, LHSC - University Hospital, 339 Windermere Rd London, Ontario, N6A5A5, Canada. Email: rick.mclachlan@lhsc.on.ca. 


\section{Which is preferable, depth or subdural recording?}

Various arguments have been put forward advocating for both of these techniques each of which has its own strengths and weaknesses. Depth electrodes are better tolerated by patients than subdural strips which induce more headache and malaise while they remain in situ. However depth electrodes have a higher risk, albeit a low one, of intracerebral hemorrhage or abscess and require expensive stereotactic equipment to implant. Further, the penetrating morphological damage to brain areas that are not subsequently resected provides a possible substrate for functional or epileptogenic disturbance. Subdural grids have the highest overall morbidity ${ }^{16}$ and require open craniotomy. Comparisons of depth versus subdural recording at any one centre must take into account the particular techniques for implantation and the types of electrode used at that centre. For example, to compare several multicontact depth electrodes directed to the hippocampus with subdural strips covering only the temporal neocortex will yield results favouring the former, an outcome not necessarily relevant to other centres using different implantation techniques. Individual epilepsy surgery centres have adopted one or the other or both largely based on the local neurosurgical experience and preferences.

There are electrophysiological considerations that must be taken into account when recording with intracerebral electrodes. The EEG signal is generated as an electrical dipole by the synchronous membrane potentials of a large population of pyramidal cells similarly aligned in the cerebral cortex. This potential as measured by any monopolar electrode using referential recording is proportional to the area of cortical surface seen by that electrode, also called the solid angle. ${ }^{17}$ Scalp electrodes will generate EEG signals only when synchronous pyramidal cell activity involves a wide cortical surface area of six square centimetres or more whereas subdural and particularly depth electrodes are recording from a limited area of millimetres or less. This higher "resolution" of course allows more accurate localization of ictal activity but only if the electrodes are accurately placed. As a result of their narrow electrophysiological characteristics, cerebral activity with a wide field such as generalized spike wave will be poorly "seen" by invasive recording techniques.

\section{What is done at London Health Sciences Centre?}

In the 1970s, Dr John Girvin, the only epilepsy surgeon at the time decided that subdural electrodes had advantages that made them more attractive for invasive intracranial recording than depth electrodes. He developed a unique technique for subdural coverage of the temporal lobe (see below) that has remained the primary means for invasive recording since then ${ }^{8,17}$. During the first 10 years of invasive recording, only $10-20 \%$ of investigated patients had telemetry using subdural electrodes in part because there was considerable reliance on intraoperative electrocorticography (ECoG) under neuroleptanalgesia which was done in all cases. In contrast to other centres which have decreased the number of invasive recordings from $100 \%$, these have increased to $40-50 \%$ at our centre while ECoG is now carried out only in selected cases, a necessity in these times of tight operating room scheduling. The likelihood of subdural recordings being done is much higher at our centre in extratemporal cases $(60 \%)$ compared to those with temporal lobe epilepsy (30\%). Although we routinely use subdural recording, depth electrode recordings are used in selected cases when the putative seizure focus is in an area such as the insula not accessible to coverage with subdural electrodes. Thus there seems to be more consensus now on the need for invasive recording as many centres that relied heavily on it have reduced their numbers while others like ours have increased utilization.

\section{What are the indications for invasive recording?}

Scalp recording along with other investigations may fail to satisfactorily localize the seizure focus but these will provide information that allows the formulation of a working hypothesis to potentially resolve the diagnostic problem using invasive recording and direct the placement of depth or subdural electrodes. Having a specific hypothesis as to where the seizures arise will prevent embarking on a "fishing expedition" with placement of a vast array of electrodes in the hope of covering the focus. On the other hand, too limited intracranial electrode coverage may miss the focus or worse give false localization when only an area to which the seizure spreads is covered.

In general the reasons for consideration of invasive recording are as follows: seizures localized but not lateralized (especially from the temporal lobes), seizures lateralized but not localized (extra temporal convexity), seizures neither lateralized or localized (supplementary motor area), seizure location discrepant with other data (right mesial temporal sclerosis but seizures predominate left temporal), seizures involve eloquent cortex (rolandic, speech), seizure localization in relation to lesion.

\section{What are the surgical techniques for implantation of intracranial electrodes?}

Depth electrodes are placed directly into the brain through separate small holes in the skull. The location and number of depth targets is dependent on the hypothesis being tested and the results of the non-invasive investigations. Once a target is chosen, a trajectory is planned using 3-dimensional MR imaging with particular care taken to avoid eloquent cortex and vascular structures. Once the trajectories and targets have been chosen, the electrode trajectories are localized using frame-based or frameless stereotaxy or, more recently, with the assistance of surgical robots. ${ }^{18}$ Once the trajectory has been acquired, the electrodes are inserted manually. Depth electrodes have the advantage of being relatively straightforward technically to insert and they are excellent for targeting specific lesions or anatomical structures (eg. hippocampus or insula). In our experience, they are also better tolerated by the patient than are subdural electrodes. However, one major shortfall of this technique is the relative inability to provide dense spatial coverage and to widely sample large cortical areas, including the mesial and inferior brain surfaces. In addition, some specialized equipment is required to insert depth electrodes.

As opposed to the smaller openings required for depth electrodes, larger exposures are required for subdural electrodes. Subdural grid electrodes are inserted by craniotomy and subdural strip electrodes are inserted either by craniotomy or through burr holes. In our centre, the preferred technique has 
been to insert subdural strip electrodes through burr holes. With appropriately placed holes, electrodes can be placed over any cortical surface, including the mesial and inferior temporal, inferior occipital, orbitofrontal and the entire mesial hemisphere. As mentioned, subdural electrodes have the advantage of excellent spatial resolution and the ability to sample any cortical surface, with the notable exception of the insular cortex. In addition, besides the electrodes themselves, no special equipment is required for their insertion. The major disadvantage of subdural electrodes is their inability to sample deeper structures or lesions, which is a task more suited to depth electrodes. The one notable exception to this would be the hippocampus, which although easily targeted with depth electrodes, can be sampled very reliably, with an inferomesially placed subdural electrode lying medial to the collateral sulcus. 8 A small percentage of patients, almost all with extratemporal epilepsy, will require supplementary insertion of additional electrode strips if the suspected seizure focus is adjacent to but not covered by the originally placed electrodes. ${ }^{19}$

\section{What are the risks of invasive recording?}

As is the case with all invasive procedures, there are risks associated with the insertion of intracranial electrodes. The most commonly reported complications are hemorrhage, infection, cerebral infarction, CSF leak, transient neurological deficits, edema and mass effect. Of these, infection and hemorrhage are the commonest serious complications. Although the reported incidence of these complications is variable, larger series have demonstrated that the rate of serious complications for depth is actually quite low, ranging from 1-4\%.20-24 Tanriverdi et al reported on a very large series of patients who underwent depth electrode insertion at the Montreal Neurological Institute. ${ }^{25}$ In 491 patients who had 6415 depth electrodes inserted, no deaths occurred and the combined rate of hemorrhage and intracranial infection was $2.6 \%$. Including minor transient complications, the overall rate was $7.1 \%$. The complication rate for subdural electrodes is more variable, likely due to the fact that most series combine complication rates for subdural grids and strips. Wyler et al looked exclusively at patients undergoing subdural strip electrode insertion and indentified complications in only $0.85 \%$ of 175 patients. ${ }^{26}$ The most common complications in our series of patients with subdural electrodes were infection and intracranial hemorrhage. ${ }^{27} \mathrm{We}$ found that the rate of complications with subdural grids (13\%) was considerably higher at LHSC than that for subdural strips (3\%).

\section{What is the outcome of surgery after invasive recording?}

Since invasive recording is usually done when seizure localization is difficult and there is no well defined lesion, one might expect a less favourable outcome from epilepsy surgery in this group. One quarter of patients who have invasive recordings at LHSC do not go on to resective surgery most commonly because more than one seizure focus is found. Of 113 patients followed for one year after surgery, 53\% were seizure free after temporal lobectomy and $41 \%$ after extratemporal resection, both somewhat lower success rates than generally expected. ${ }^{28} \mathrm{Age}$ at surgery had a major impact on outcome as only $20 \%$ of those who had invasive recordings with subsequent surgery over age 40 years became seizure free.

\section{REFERENCES}

1. Sperling MR, Shewmon DA. General Principles for Presurgical Evaluation. In: Engel JJ, Pedley TA, eds. Epilepsy: A Comprehensive Textbook. Philadelphia: Lippincott-Raven; 1997:1697-705.

2. Bancaud J, Angelergues R, Bernouilli C, et al. [Functional stereotaxic exploration (stereo-electroencephalography) in epilepsies]. Rev Neurol (Paris). 1969;120:448.

3. Bancaud J, Angelergues R, Bernouilli C, et al. Functional stereotaxic exploration (SEEG) of epilepsy. Electroencephalogr Clin Neurophysiol. 1970;28:85-6.

4. Olivier A, Gloor P, Quesney LF, Andermann F. The indications for and the role of depth electrode recording in epilepsy. Appl Neurophysiol. 1983;46:33-6.

5. Spencer SS. Depth electroencephalography in selection of refractory epilepsy for surgery. Ann Neurol. 1981;9:207-14.

6. Adelson PD, Black PM, Madsen JR, et al. Use of subdural grids and strip electrodes to identify a seizure focus in children. Pediatr Neurosurg. 1995;22:174-80.

7. Cohen-Gadol AA, Spencer DD. Use of an anteromedial subdural strip electrode in the evaluation of medial temporal lobe epilepsy. Technical note. J Neurosurg. 2003;99:921-3.

8. Steven DA, Andrade-Souza YM, Burneo JG, McLachlan RS, Parrent AG. Insertion of subdural strip electrodes for the investigation of temporal lobe epilepsy. Technical note. J Neurosurg. 2007;106:1102-6.

9. Wyler AR, Ojemann GA, Lettich E, Ward AA, Jr. Subdural strip electrodes for localizing epileptogenic foci. J Neurosurg. 1984;60:1195-200.

10. Spencer SS, Spencer DD, Williamson PD, Mattson R. Combined depth and subdural electrode investigation in uncontrolled epilepsy. Neurology. 1990;40:74-9.

11. Behrens E, Zentner J, van Roost D, Hufnagel A, Elger CE, Schramm J. Subdural and depth electrodes in the presurgical evaluation of epilepsy. Acta Neurochir (Wien). 1994;128:84-7.

12. van Veelen CW, Debets RM, van Huffelen AC, et al. Combined use of subdural and intracerebral electrodes in preoperative evaluation of epilepsy. Neurosurgery. 1990;26:93-101.

13. Spencer SS, Spencer DD, Williamson PD, Mattson RH. The localizing value of depth electroencephalography in 32 patients with refractory epilepsy. Ann Neurol. 1982;12:248-53.

14. Gloor, P. Neurosurgical management of the epilepsies. Adv Neurol. 1975; 9: 59-105

15. So EL. Integration of EEG, MRI, and SPECT in localizing the seizure focus for epilepsy surgery. Epilepsia. 2000;41 Suppl 3: S48-54.

16. Wellmer J, von der Groeben F, Klarmann U, Weber C, Elger CE, Urbach $\mathrm{H}$, Clusmann $\mathrm{H}$, von Lehe M. Risks and benefits of invasive epilepsy surgery workup with implanted subdural and depth electrodes. Epilepsia. 2012; 10:1528-1167

17. Dubeau F, McLachlan RS. Invasive electrograhic recording techniques in temporal lobe epilepsy. Can J Neurol Sci. 2000; 27 Suppl 1: S29-34

18. Cossu M, Cardinale F, Castana L, et al. Stereoelectroencephalography in the Presurgical Evaluation of Focal Epilepsy: a Retrospective Analysis of 215 Procedures. Neurosurgery. 2005;57:706-18

19. MacDougall KW, Steven DA, Parrent AG, Burneo JG. Supplementary implantation of intracranial electrodes in the evaluation for epilepsy surgery. Epilepsy Res. 2009;87:9510120.

20. Pilcher WH, Roberts DW, Flanigin HF, Crandall PH, Wieser HG, Ojemann GA. Complications of epilepsy surgery. In: Engel J, ed. Surgical Treatment of the Epilepsies. 2 ed. New York: Raven Press; 1993:565-81.

21. de Almeida, N. A, Olivier A, et al. Efficacy of and morbidity associated with stereoencephalography using computed tomography- or magnetic resonance imaging-guided electrode implantation. J Neurosurg. 2006;104:483-7.

22. Van Buren JM. Complications of surgical procedures in the diagnosis and treatment of epilepsy. In: Engel J, ed. Surgical Treatment of the Epilepsies. New York: Raven Press; 1987:46575. 
23. Ross DA, Brunberg JA, Drury I, Henry TR. Intracerebral depth electrode monitoring in partial epilepsy: the morbidity and efficacy of placement using magnetic resonace image-guided stereotactic surgery. Neurosurgery. 1996;39:327-34.

24. Spencer SS, So NK, Engel J, Williamson PD, Levesque MF, Spencer DD. Depth electrodes. In: Engel J, ed. Surgical Treatment of the Epilepsies. New York: Raven Press; 1993:35976.

25. Tanriverdi T, Ajlan A, Poulin N, Olivier A. Morbidity in epilepsy surgery: an experience based on 2449 epilepsy surgery procedures from a single institution. J Neurosurg. 2009; 110: 1111-23.
26. Wyler AR, Walker G, Somes G. The morbidity of long-term seizure monitoring using subdural strip electrodes. J Neurosurg 1991;74: 734-7.

27. Burneo JG, Steven DA, McLachlan RS, Parrent AG. Morbidity associated with the use of intracranial electrodes for epilepsy surgery. Can J Neurol Sci. 2006;33:223-7.

28. MacDougall KW, Burneo JG, McLachlan RS, Steven DA. Outcome of epilepsy surgery in patients investigated with subdural electrodes. Epilepsy Res. 2009;85:235-42 